\title{
The role of the General Practice Liaison Nurse as integrated care coordinator: A Delphi study
}

\author{
Lesley Wilkes ${ }^{* 1,2}$, Michelle Doull ${ }^{3}$, Janis Paterson ${ }^{3}$, Kate Le Cornu ${ }^{4}$, Harrison Ng Chok ${ }^{1,2}$ \\ ${ }^{1}$ School of Nursing and Midwifery, University of Western Sydney, Nepean Blue Mountains Local Health District, Australia \\ ${ }^{2}$ Centre for Nursing Research and Practice Development, Nepean Hospital, Penrith, Australia \\ ${ }^{3}$ Nepean Blue Mountains Local Health District, Australia \\ ${ }^{4}$ Western Sydney Local Health District, Australia
}

Received: March 14, 2016

DOI: $10.5430 /$ cns.v4n3p67
Accepted: April 28, 2016

Online Published: June 21, 2016

URL: http://dx.doi.org/10.5430/cns.v4n3p67

\begin{abstract}
In New South Wales (NSW), Australia, the position of General Practice Liaison Nurse (GPLN) was established in the early 2000s to support integrated care of patients/clients by encouraging inter-professional/inter-organisational collaboration. Other terms used for this role include liaison nurse, integrated care co-ordinator, and primary care liaison nurse. The purpose of this study was to clarify the role of these nurses working in the community in outer Sydney, NSW, using a three round Delphi Technique with 19 GPLNs working in the community specialist streams of child and family, complex and chronic care, and mental health. Findings showed that the GPLN worked across 11 role domains: co-ordinator, educator, communicator, advocate, change agent, manager, collaborator, negotiator, team leader and clinician. Functions were delineated for each domain role and there were a total of 33 functions. This first study in Australia to delineate the role of the GPLN shows that while each of the domains is important, the dominant domain is co-ordination with all the other ten needed to implement this important role. The clarity of the role is important to help the nurses themselves, management, and also other stakeholders to understand their expectations of the GPLN.
\end{abstract}

Key Words: General practice liaison nurse, Integrated care coordinator, Role domain and role functions, Delphi technique

\section{INTRODUCTION}

The major single issue facing health care systems today is poor service integration and care coordination. ${ }^{[1]}$ To encourage inter-professional/inter-organisational collaboration, federal and state governments have introduced initiatives to improve care coordination, ${ }^{[2,3]}$ one of which was the establishment of liaison nurse positions. These positions are known by various titles, e.g. Liaison Nurse, Integrated Care Coordinator, Primary Care Liaison Nurse or General Practice Liaison Nurse (GPLN). This paper reports the results of a Delphi Technique study which aimed to delineate and clar- ify the role of the GPLN in Primary Care and Community Health settings in Greater Western Sydney, New South Wales (NSW), Australia. Since the commencement of this study, some of the GPLN positions have been renamed and are now known as Integrated Care Coordinator, although the position will be referred to in this paper as GPLN.

\section{Background}

In countries such as United Kingdom, Ireland, United States of America and Australia, liaison nurse positions have been established in a variety of speciality areas. These include epilepsy, ${ }^{[4,5]}$ genetics, ${ }^{[6]}$ multiple sclerosis, ${ }^{[7]}$ mental

*Correspondence: Lesley Wilkes; Email: 1.wilkes@westernsydney.edu.au; Address: Centre for Nursing Research and Practice Development, School of Nursing and Midwifery, Western Sydney University, Nepean Blue Mountains Local Health District, PO Box 63, PENRITH NSW 2751, Australia. 
health, ${ }^{[8-10]}$ aged care, ${ }^{[11,12]}$ liaison for discharge from emergency departments, ${ }^{[13]}$ chronic and complex care, at risk children and families ${ }^{[14,15]}$ and chronic disease management. ${ }^{[16]}$ Overall, this literature indicates that liaison nurses play an integral role in improving communication and care coordination.

Poor communication between service providers, especially with General Practitioners (GPs), has been found to lead to problems for patients being discharged or followed up post discharge from hospital, for people who are older ${ }^{[13]}$ or with mental illness, ${ }^{[9]}$ and identified as one of the barriers to service integration. ${ }^{[3]}$ Liaison nurses have been found to play a role in improving communication and patient outcomes. A Dublin study at St Vincent's University Hospital reports the usefulness of a discharge liaison position in the Emergency Department. This position facilitates planned discharge home for older people over 65 years of age and organises follow up appointments with GP and specialist clinics, facilitating better management of health conditions and improving integration of multiple care providers. ${ }^{[13]}$ Earlier in a review of Outpatient Geriatric Clinics in the United Kingdom, Donald \& Berman suggested that liaison nurses could be used instead of post discharge follow-up clinic visits to identify early functional problems at home. ${ }^{[11]}$

For a decade, it has been recognised that patients with chronic conditions and complex care needs benefit from an integrated approach to chronic disease management. ${ }^{[17]}$ Identifying a person's needs and communicating effectively with relevant services are essential activities of integrated care, especially for those who have multiple comorbidities and require support from multiple services. An Australian study found that GPs lacked confidence in identifying social problems of older patients and communicated poorly with Aged Care Assessment Teams. ${ }^{[12]}$ GPs in the study reported the Aged Care Liaison Nurse was extremely useful in helping GPs to determine a patient's needs, to identify services required, and to prepare a care plan. This model was acceptable to the participating GPs and they recognised that adding a care coordinator was beneficial to general practice and did not undermine the GP's role. ${ }^{[12]}$

The liaison nurse role is well established within mental health services and has evolved over the past 50 years with the recognition that the person in the role requires inherent interpersonal skills and undertakes an educational role for awareness raising and capacity building. ${ }^{[10]}$ Van der Watt described the evolution of the consultation-liaison nurse from its origins in consultation psychiatry in the United States in the 1960s, followed by introduction to the UK in the 1970s, then Australia in the 1980s. ${ }^{[10]}$ She cited good communication and social skills were required to handle relationships and create a constructive environment through teamwork, cooperation and negotiation, and describes the liaison nurse as understanding the "worlds" of patients and health professionals. Through her personal reflection, Van der Watt described how the consultation-liaison nurses in mental health were pivotal in raising awareness and understanding of the impact of mental illness on physical health in the general hospital setting. Mental Health Liaison Nurses at Prince of Wales Hospital, Sydney, have been established and are also used to build, sustain and maintain the capacity of non-mental health staff in generalist settings. ${ }^{[8]}$

In NSW, Australia, GPLNs were established in some primary health care settings to assist GPs with health assessment, care planning and case conferencing activities for patients with chronic conditions and complex care needs, ${ }^{[17]}$ following the introduction of the Australian Government's Enhanced Primary Care Program in 1999, now replaced with Chronic Disease Management Program. ${ }^{[18]}$ GPLNs were found to be pivotal in bringing general practice and community health care services together, initially through being co-located in the then Divisions of General Practice, ${ }^{[19]}$ and more recently through the formal partnership of HealthOne, a NSW State Health initiative launched in 2007 that brings Commonwealth funded GPs and State funded Primary Care and Community Health program services together. ${ }^{[3]}$ Two HealthOne sites in NSW, Mt Druitt and Northern Sydney, have been evaluated to date. ${ }^{[15,16]}$

The GPLN is shown to be critical to improving integrated care for patients with complex social issues and care needs. $\mathrm{McNab}$ et al. described the role of the GPLN in a community health setting working with vulnerable communities by drawing on research findings from a larger mixed-method evaluation of the HealthOne Mt Druitt program within Western Sydney. ${ }^{[15]}$ The priority target areas included at-risk children and families as well as people with chronic and complex care needs. Evidence showed that the GPLN activities improved coordination, communication and integration of services. The GPLNs were described as leaders and initiators of cultural change for all partners and organisations in the primary health care sector and vital to almost all aspects of the implementation, operation and sustainability of HealthOne Mt Druitt. ${ }^{[14]}$ The Northern Sydney HealthOne study showed the involvement of the GPLNs led to better connections between health professionals, patients and their families. ${ }^{[16]}$ This included better integration of care, including information sharing and identification of psychosocial issues, improved outcomes for complex patients, and reduced patient stress. Prior to the evaluation of HealthOne, little was known about GPLN roles in primary health settings. Both 
$\mathrm{McNab}$ et al. and Bloomfield \& Gordon discuss the role the GPLN plays in the success of HealthOne within the broader context of achieving improved patient outcomes rather than the functions of the role. ${ }^{[15,16]}$ Bloomfield \& Gordon highlighted that there was a lack of clarity of the role of the GPLN. ${ }^{[16]}$ This study aims to delineate the role domains and functions of the GPLN working in the community in Greater Western Sydney.

\section{MeTHODS}

The Delphi Technique uses a panel of "experts" to develop a collective consensus on a topic through the use of sequential questionnaires, ${ }^{[20]}$ which is a method where the views of experts are used to gain a consensus on an issue. It has been used extensively in nursing to define clinical roles. ${ }^{[20]}$ Some of the advantages of the Delphi technique is its ability to gain key characteristics, use multiple iterations of data collection and provide some simple statistical analysis of the data. ${ }^{[21]}$ In this study, a series of three rounds of questionnaires were conducted with GPLN experts, and interspersed with regulated feedback which informed the modification of subsequent rounds to determine consensus and define the domains and functions of the role of the GPLN in the community health context in Greater Western Sydney.

\subsection{Setting}

The GPLNs involved in this Delphi study were invited from 17 community health centres in the Western Sydney $(n=7)$ and Nepean Blue Mountains Local Health Districts $(n=10)$, NSW, Australia.

\subsection{Population and sample}

The sample consisted of 19 GPLNs (15 of which completed all three of the Delphi round surveys and the remaining four GPLNs completed less than two), from Child and Family, Chronic and Complex, and Mental Health specialty streams, who are deemed experts in their field based on the years of experience and positions held. Some nurses have held the position for less than a year but were still considered able to provide expert critique of the role (see Table 1).

\subsection{Recruitment}

The GPLNs were contacted through professional networks and invited to voluntarily participate in the project via email. Participant information sheets and consent forms attached to emails were collected from those wishing to participate in the study. Round 1 questionnaire and a demographic survey were sent to the respondents who agreed to participate which they were asked to return to the researchers by email.
Table 1. Demographics of the participants who completed the Delphi Technique surveys $(n=19)$

\begin{tabular}{|c|c|}
\hline & Demographics $(n=19)$ \\
\hline \multirow{2}{*}{ Gender } & Male: 3 (16\%) \\
\hline & Female: 16 (84\%) \\
\hline \multirow{3}{*}{ Age } & Mean :50.3 years \\
\hline & SD: 8.9 \\
\hline & Range: 30-63 years \\
\hline \multirow{3}{*}{ Qualifications attained } & Certificate: 9 (47.4\%) \\
\hline & Diploma: 3 (15.8\%) \\
\hline & Masters: 7 (36.8\%) \\
\hline \multirow{3}{*}{ Years as RN } & Mean: 26.8 years \\
\hline & SD: 9.9 \\
\hline & Range: 7-39 years \\
\hline \multirow{3}{*}{ Years worked as a GPLN } & Mean: 2.8 years \\
\hline & $S D: 2.9$ \\
\hline & Range: 4mths-12.7 years \\
\hline \multirow{3}{*}{ Specialty areas worked } & Child and Family: 8 \\
\hline & Chronic and Complex: 10 \\
\hline & Mental Health: 1 \\
\hline
\end{tabular}

Note. RN: Registered Nurse; GPLN: General Practice Liaison Nurse

\subsection{Data collection}

Each round of the Delphi technique questionnaires took approximately 15 minutes to complete.

The Round 1 questionnaire consisted of 60 items that were developed by two GPLN Clinical Nurse Consultant (CNC) investigators from their experience in working in the role, their position description and other relevant literature. A six point Likert scale was used for each role function (from role least important to most important) and the nurses were asked to grade its importance as: not important, peripherally important, minor importance, moderately important, important or crucial/important. The nurses were also asked to add any role function that they thought was missing to the list.

The Round 2 questionnaire consisted of 45 items. In this round, the nurses were asked if each of the role functions should be included in role description by answering yes or no for each item.

The third and final round consisted of 33 items. These items (role functions) were sorted into 11 role domains by the research team with their associated functions. The experts were asked to answer "yes" or "no" as to whether the functions were correctly categorised under the relevant role domain. They were instructed to provide an alternate role domain for any particular function that they felt had not been sorted appropriately.

\subsection{Data analysis}

Responses to each round of the surveys were tallied and frequencies calculated. A content validity of 0.8 (80\%) was 
used for each round. ${ }^{[22]}$ Inter-rata reliability was achieved by all members of the research team meeting to discuss each round's results and how and what should be included in the next round of questionnaires. A comparison of differences related to age, sex, position and specialty streams was attempted but not completed, as the number of cells was less than five. Demographic data were tallied, frequencies and percentages calculated and tabulated.

\subsection{Ethical considerations}

Approvals were obtained from Nepean Blue Mountains Local Health District Human Ethics Research Committee. Site Specific Approval was also obtained from the Managers of the participating Community Health Centres in Nepean Blue Mountains, Western Sydney Local Health Districts and Western Sydney University.

\section{RESUlts}

Nineteen nurses working as GPLNs or in an equivalent position, such as integrated care coordinators, were involved in one or more of the three rounds (one participant dropped out in round two, with an additional two dropping out in round three and an additional two were included in rounds two and three). Of the nineteen nurses, three were male (16\%), and sixteen were female ( $84 \%$ ); ten were aged over 51 years $(53 \%)$ and had an average of 27 years of experience as registered nurses. All the nurses were based in community health centres in Local Health Districts in Western Sydney and the Blue Mountains, NSW, Australia, and all had completed postgraduate degrees or Diplomas and Certificates. Seven nurses worked in Chronic and Complex Care, seven in Child and Family Health and one in Mental Health, who only completed round one of the questionnaires. Most of the nurses had worked in the designated role for over 2 years. The Child and Family nurses' opinion were consistent with that of the Chronic and Complex nurses and consensus on various functions and domains that were similar so the research team decided to report these as one group.

\section{Outcomes of Delphi rounds}

A summary of the Delphi technique process for this study is depicted in Figure 1. The results for each round will be provided separately.

Round 1: Fifteen nurses returned the survey during the first round. From the 60 items relating to role function (see Table 2) given to the nurses to grade from "not important" to "crucial", 42 were considered by $80 \%$ (content validly of 0.80 ) of the respondents to be "crucially important" or "important". In addition, the nurses added three new items. The final 44 items (with added items from respondents including 42, 43, and 44) are displayed in Table 3 with their content validity score.

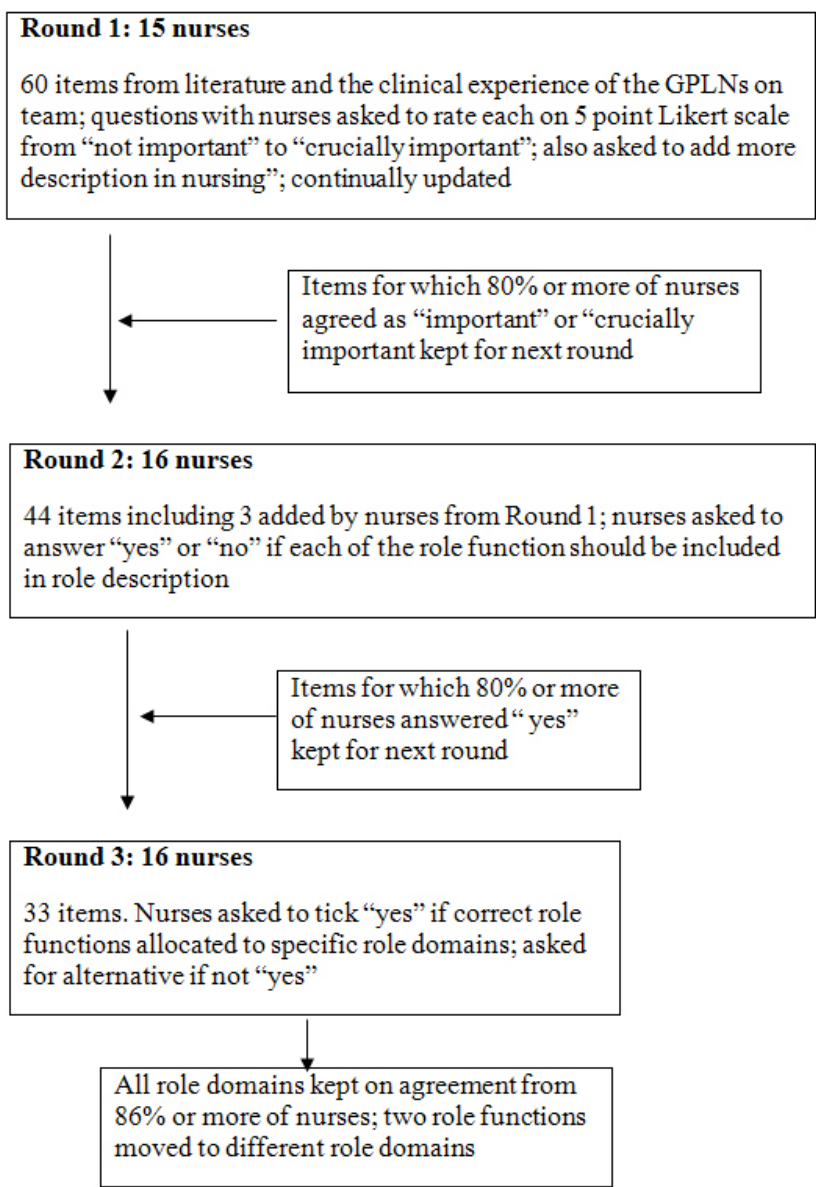

Figure 1. Delphi technique process to determine role of GPLN

Round 2: Sixteen nurses returned the survey (one nurse dropped out and two other nurses volunteered to participate). Of the 45 items that were selected from Round 1, 33 items were given a content validity of 0.90 or greater $(90 \%$ yes response, see Table 4). These were categorised into 11 role domains with their appropriate functions that are listed in Table 5 with the content validity score. Sixteen of the 45 functions had a content validity score of 1.00 with the rest (17) having a content validity score of 0.94 which is equivalent with one of the 16 respondents answering no and showing strong agreement with functions finally categorised into the 11 role domains nominated by the researchers.

Round 3: Sixteen nurses returned the survey (two participants dropped out from Round 2 and two other nurses volunteered to participate). All functions were considered by over $90 \%$ of the nurses to be under the correct role domain (see Table 5). For some items (1.1, 1.2, 1.3, 1.5, 2.1, 3.2, 5.1), the nurses provided alternative words to items but this was not considered by the researchers as very different. One nurse 
felt that item 7.2 under manager role domain would fit better under advocate and the researchers changed this (highlighted function 5.3). Item 5.1 was considered by two nurses to fit better under coordinator rather than advocate (highlighted function 1.7). Table 6 provides a list of the 11 role domains and functions finally agreed upon.

Table 2. List of 60 items describing GPLN role functions provided to sample for Round 1

GP Liaison Nurse Role Functions

1. A nurse who provides a liaison role between health care professionals to facilitate coordinated, integrated care

2. A nurse who is a link between the hospital and community

3. A nurse expert in co-ordinating and facilitating inter-professional inter-organisational case conferences

4. A nurse who facilitates and encourages multidisciplinary teamwork

5. A nurse who improves communication between the hospital, community health and general practice

6. A negotiator between health and service providers with different perceptions, drivers and expectations regarding care provision

7. A nurse who is seen by service providers as a person who can provide information on referral pathways for clinical or psychosocial services

8. A supporter of primary care providers and care givers in navigating the health care system

9. A nurse who facilitates integrated health care across vulnerable client groups

10. A nurse who empowers people to navigate the health care and community support systems

11. A consultant in care coordination for health providers in the acute and community sectors of government and non-government organisations

12. A nurse who can advise on current NSW Ministry of Health and local health programs and initiatives for target groups of people

13. A nurse who is seen by service providers as a person who can provide information about general practice

14. A nurse who is seen by service providers as a person who can provide advice on Medicare items used for Chronic Disease Management, Mental Health and Health Checks in general practice

15. A nurse who factors Federal, State and local initiatives into client care

16. A member of multidisciplinary teams encompassing acute, community, government and non-government organisations and private business

17. A nurse who collaborates effectively with a broad range of people regarding service provision

18. A nurse who co-ordinates and facilitates multidisciplinary case reviews

19. A nurse who facilitates ongoing individual case review and management planning for clients/families/carers with complex needs

20. A nurse who initiates and encourages ongoing communication between care and service providers regarding client/patient care

21. A nurse who works across the broader section of the community

22. A nurse who builds bridges between service providers

23. A nurse who networks with internal and external service providers

24. A nurse who works with service providers internal and external to health

25. A triage manager of a person's overall care needs

26. A nurse who fosters good working relationships across all sectors, including government, non-government and private service providers

27. A nurse who leads a team

28. A nurse who facilitates and encourages inter professional teamwork

29. A resource person to the hospital, community and general practice staff

30. A provider of educational material relating to chronic conditions, complex care and psychosocial support

31. A provider of information regarding community support services

32. A nurse who identifies appropriate services options and initiates referral

33. A nurse who gathers and disseminates information using a variety of systems and programs

34. A nurse who facilitates health and community service access for people

35. An overseer of holistic care coordination

36. An advocate for clients/patients, their families and caregivers

37. A nurse who performs holistic client/patient assessments

38. A nurse who develops holistic interdisciplinary care plans

39. A nurse who compiles client/patient reports for dissemination to a variety of care providers

40. A nurse who monitors and reviews ongoing client management

41. A nurse who facilitates 'follow through' of clinicians' planned tasks

42. A nurse who applies innovation to complex care management

43. A nurse who mediates when necessary

44. A nurse who analyses complex clinical situations

45. A mentor for new staff in the specialty area

46. A nurse who provides supervision to staff

47. A nurse who supports clients, carers and staff with a person centred approach

48. A nurse who applies expert knowledge to better inform clinical practice

49. A researcher in the latest information regarding best practice for integrated care coordination for complex and vulnerable client groups

50. A nurse who identifies gaps in services / programs

51. A nurse who contributes to ongoing quality improvement in service delivery

52. A nurse who facilitates change

53. A nurse who contributes to research projects

54. A nurse who contributes to the development of clinical structures / processes

55. A nurse who provides consultancy in the development of programs or new initiatives

56. A nurse who is a member of committees which promote the health and wellbeing of people and communities

57. A nurse who develops educational material relating to their specialty

58. A nurse who delivers educational presentations

59. A nurse who identifies and organises topics/guest speakers for education / in-service

60. A nurse who is able to prioritise complex and competing schedules and workload 
Table 3. Forty-one role functions of GPLN role chosen by at least $80 \%$ of nurses (Content validly $=0.80$ ) in Round 1 with three extra items added by the sample $\left(^{*}\right)$ - total of 44

\begin{tabular}{|c|c|c|}
\hline \multicolumn{2}{|r|}{ General Practice Liaison Nurse (GPLN) role functions } & \multirow{2}{*}{$\begin{array}{c}\text { Content validity } \\
0.93\end{array}$} \\
\hline 1. & A nurse who provides a liaison role between health care professionals to facilitate coordinated, integrated care & \\
\hline 2. & A nurse who is a link between the hospital and community & 0.93 \\
\hline 3. & A nurse expert in co-ordinating and facilitating inter-professional inter-organisational case conferences & 0.93 \\
\hline 4. & A nurse who facilitates and encourages multidisciplinary teamwork & 0.93 \\
\hline 5. & A nurse who improves communication between the hospital, community health and general practice & 0.93 \\
\hline 6. & A negotiator between health and service providers with different perceptions, drivers and expectations regarding care provision & 0.93 \\
\hline 7. & $\begin{array}{l}\text { A nurse who is seen by service providers as a person who can provide information on referral pathways for clinical or } \\
\text { psychosocial services }\end{array}$ & 1.00 \\
\hline 8. & A supporter of primary care providers and care givers in navigating the health care system & 0.87 \\
\hline 9. & A nurse who facilitates integrated health care across vulnerable client groups & 1.00 \\
\hline 10. & A nurse who empowers people to navigate the health care and community support systems & 1.00 \\
\hline 11. & $\begin{array}{l}\text { A consultant in care coordination for health providers in the acute and community sectors of government and non-government } \\
\text { organisations }\end{array}$ & 1.00 \\
\hline 12. & A nurse who can advise on current NSW Ministry of Health and local health programs and initiatives for target groups of people & 0.93 \\
\hline 13. & A nurse who is seen by service providers as a person who can provide information about general practice & 0.93 \\
\hline 14. & A nurse who factors Federal, State and local initiatives into client care & 0.86 \\
\hline 15. & $\begin{array}{l}\text { A member of multidisciplinary teams encompassing acute, community, government and non-government organisations and } \\
\text { private business }\end{array}$ & 0.87 \\
\hline 16. & A nurse who collaborates effectively with a broad range of people regarding service provision & 0.93 \\
\hline 17. & A nurse who initiates and encourages ongoing communication between care and service providers regarding client/patient care & 0.93 \\
\hline 18. & A nurse who works across the broader section of the community & 1.00 \\
\hline 19. & A nurse who builds bridges between service providers & 0.93 \\
\hline 20. & A nurse who networks with internal and external service providers & 0.93 \\
\hline 21. & A nurse who works with service providers internal and external to health & 1.00 \\
\hline 22. & $\begin{array}{l}\text { A nurse who fosters good working relationships across all sectors, including government, non-government and private service } \\
\text { providers }\end{array}$ & 0.93 \\
\hline 23. & A nurse who facilitates and encourages inter professional teamwork & 1.00 \\
\hline 24. & A resource person to the hospital, community and general practice staff & 1.00 \\
\hline 25. & A provider of information regarding community support services & 0.93 \\
\hline 26. & A nurse who gathers and disseminates information using a variety of systems and programs & 0.87 \\
\hline 27. & A nurse who facilitates health and community service access for people & 0.93 \\
\hline 28. & An overseer of holistic care coordination & 0.87 \\
\hline 29. & An advocate for clients/patients, their families and caregivers & 0.87 \\
\hline 30. & A nurse who applies innovation to complex care management & 0.87 \\
\hline 31. & A nurse who mediates when necessary & 0.93 \\
\hline 32. & A nurse who analyses complex clinical situations & 0.80 \\
\hline 33. & A nurse who supports clients, carers and staff with a person centred approach & 1.00 \\
\hline 34. & A nurse who applies expert knowledge to better inform clinical practice & 0.93 \\
\hline 35. & $\begin{array}{l}\text { A researcher in the latest information regarding best practice for integrated care coordination for complex and vulnerable client } \\
\text { groups }\end{array}$ & 0.87 \\
\hline 36. & A nurse who identifies gaps in services / programs & 0.87 \\
\hline 37. & A nurse who contributes to ongoing quality improvement in service delivery & 1.00 \\
\hline 38. & A nurse who facilitates change & 0.87 \\
\hline 39. & A nurse who contributes to the development of clinical structures / processes & 0.87 \\
\hline 40. & A nurse who is a member of committees which promote the health and wellbeing of people and communities & 1.00 \\
\hline \multirow[t]{4}{*}{41.} & A nurse who is able to prioritise complex and competing schedules and workload & 0.93 \\
\hline & A nurse who maintains ongoing communication between care and service providers regarding client/patient care. & * \\
\hline & A nurse who facilitates interdisciplinary care plans. & ${ }^{*}$ \\
\hline & A nurse with excellent communication and negotiation skills & * \\
\hline
\end{tabular}


Table 4. The 33 functions of the GPLN role chosen by at least $80 \%$ of nurses (Content validity $=0.80$ ) in Round 2

\begin{tabular}{|c|c|}
\hline Role functions & Content validity \\
\hline A nurse who provides a liaison role between health care professionals to facilitate coordinated care & 1.00 \\
\hline - A nurse who is a link between hospital and community & 1.00 \\
\hline - A nurse expert in co-ordinating and facilitating inter-organisational case management & 0.94 \\
\hline $\begin{array}{l}\text { - A consultant in care co-ordination for health providers in the acute and community sectors of government and } \\
\text { non-government organisation }\end{array}$ & 0.94 \\
\hline - A nurse who facilitates health and community service access for people & 0.94 \\
\hline - A nurse who facilitates interdisciplinary care plans & 0.94 \\
\hline - A nurse who is seen by service providers as the person who can provide information about general practice & 1.00 \\
\hline - A resource person to the hospital, community and general practice staff & 1.00 \\
\hline - A provider of information regarding community support services & 1.00 \\
\hline - A nurse who gathers and disseminates information using a variety of systems and programs & 1.00 \\
\hline $\begin{array}{l}\text { - A researcher in the latest information regarding best practice for integrated care co-ordination for complex and vulnerable } \\
\text { populations }\end{array}$ & 1.00 \\
\hline • A nurse who improves communication between the hospital, community health and general practice & 1.00 \\
\hline - A Nurse who maintains ongoing communication between care and service providers regarding client/patient care & 0.94 \\
\hline - A nurse with excellent communication and negotiation skills & 1.00 \\
\hline $\begin{array}{l}\text { - A nurse who is seen by service providers as a person who can provide information on referral pathways for clinical and } \\
\text { psychosocial services }\end{array}$ & 0.94 \\
\hline - A supporter of primary health care providers and care givers in navigating the health care system & 1.00 \\
\hline $\begin{array}{l}\text { - A nurse who can advise on current NSW Ministry of Health and local health programs and initiatives for target groups of } \\
\text { people }\end{array}$ & 0.94 \\
\hline - A nurse who facilitates integrated health care across vulnerable populations & 1.00 \\
\hline - A nurse who empowers people to navigate the health care and community support systems & 0.94 \\
\hline - An advocate for clients/patients, their families and caregivers & 0.94 \\
\hline - A nurse who identifies gaps in services/programs & 1.00 \\
\hline - A nurse who contributes to ongoing quality improvement in service industry & 1.00 \\
\hline - A nurse who facilitates change & 0.94 \\
\hline - A nurse who contributes to the development of clinical structures/processes & 0.94 \\
\hline - A nurse who is a member of committees who promote the health and wellbeing of people and communities & 0.94 \\
\hline - A nurse who is able to prioritise complex and competing schedules and workload & 1.00 \\
\hline - A nurse who collaborates effectively with a broad range of people regarding service provision & \\
\hline - A nurse who works with service providers internal and external to health & 0.94 \\
\hline - A nurse who networks with internal and external service providers & 1.00 \\
\hline $\begin{array}{l}\text { - A nurse who fosters working relationships across all sectors, including government, non-government and private service } \\
\text { providers }\end{array}$ & 0.94 \\
\hline - A nurse who facilitates and encourages multidisciplinary teamwork & 1.00 \\
\hline $\begin{array}{l}\text { - A member of multidisciplinary teams encompassing acute, community, government and non-government organisations and } \\
\text { private business }\end{array}$ & 0.94 \\
\hline - A nurse who supports clients with a person centred approach & 0.94 \\
\hline
\end{tabular}

\section{Discussion}

This study, which is the first in Australia to delineate the role functions of the GPLN, shows that this nurse specialist works under 11 role domains (see Table 6). The domains are consistent with the opinions of over $80 \%$ of the nurses involved in the study. Three specialty groups contributed to this study, so the role domains and associated functions are described generically across the child and family, chronic and complex in the community health setting. While the role functions are grouped under 11 individual domains, the
10 domains of educator, communicator, advisor, advocate, change agent, manager, collaborator, negotiator, team member and clinician are all needed to fulfil the 11th domain of coordinator being the ultimate purpose of the role. To further demonstrate this, the coordinator domain has the largest number of functions, which reflects this dominant part of the role which is enhancing person centred care across service spectrum spanning multiple specialties, disciplines, locations and organisations. Other studies confirm that the presence of a nurse coordinator role contributes to better management of 
health conditions, ${ }^{[13]}$ early identification of functional and so- As suggested by Cloninger et al. ${ }^{[2]}$ this type of integration cial problems ${ }^{[12,23]}$ and connects services providers and GPs is necessary to support clients in the community to sustain to integrate care leading to better patient outcomes. ${ }^{[12,14-16]}$ optimal wellbeing.

Table 5. Results of Round 3 when nurses asked to determine if the 33 role functions were categorised appropriately under 11 role domains for the GPLN

\begin{tabular}{|c|c|}
\hline Role domains & Content validity \\
\hline \multicolumn{2}{|l|}{ 1. Co-ordinator of client/patient care } \\
\hline - A nurse who provides a liaison role between health care professionals to facilitate coordinated care & 0.96 \\
\hline - A nurse who is a link between hospital and community & 0.96 \\
\hline - A nurse expert in co-ordinating and facilitating inter-organisational case management & 0.96 \\
\hline $\begin{array}{l}\text { - A consultant in care co-ordination for health providers in the acute and community sectors of government and } \\
\text { non-government organisation }\end{array}$ & 0.96 \\
\hline - A nurse who facilitates health and community service access for people & 1.00 \\
\hline - A nurse who facilitates interdisciplinary care plans & 1.00 \\
\hline - A nurse who facilitates integrated health care across vulnerable populations & 0.96 \\
\hline \multicolumn{2}{|l|}{ 2. Educator } \\
\hline - A nurse who is seen by service providers as the person who can provide information about general practice & 0.96 \\
\hline - A resource person to the hospital, community and general practice staff & 1.00 \\
\hline - A provider of information regarding community support services & 1.00 \\
\hline - A nurse who gathers and disseminates information using a variety of systems and programs & 1.00 \\
\hline $\begin{array}{l}\text { - A researcher in the latest information regarding best practice for integrated care co-ordination for complex and vulnerable } \\
\text { populations }\end{array}$ & 1.00 \\
\hline \multicolumn{2}{|l|}{ 3. Communicator } \\
\hline • A nurse who improves communication between the hospital, community health and general practice & 1.00 \\
\hline - A Nurse who maintains ongoing communication between care and service providers regarding client/patient care & 0.96 \\
\hline - A nurse with excellent communication and negotiation skills & 1.00 \\
\hline \multicolumn{2}{|l|}{ 4. Advisor } \\
\hline $\begin{array}{l}\text { - A nurse who is seen by service providers as a person who can provide information on referral pathways for clinical and } \\
\text { psychosocial services }\end{array}$ & 1.00 \\
\hline - A supporter of primary health care providers and care givers in navigating the health care system & 1.00 \\
\hline $\begin{array}{l}\text { - A nurse who can advise on current NSW Ministry of Health and local health programs and initiatives for target groups of } \\
\text { people }\end{array}$ & 1.00 \\
\hline \multicolumn{2}{|l|}{ 5. Advocate } \\
\hline - A nurse who empowers people to navigate the health care and community support systems & 1.00 \\
\hline - An advocate for clients/patients, their families and caregivers & 1.00 \\
\hline - A nurse who is a member of committees who promote the health and wellbeing of people and communities & 0.96 \\
\hline \multicolumn{2}{|l|}{ 6. Change agent } \\
\hline - A nurse who identifies gaps in services/programs & 1.00 \\
\hline - A nurse who contributes to ongoing quality improvement in service industry & 1.00 \\
\hline - A nurse who facilitates change & 1.00 \\
\hline \multicolumn{2}{|l|}{ 7. Manager } \\
\hline - A nurse who contributes to the development of clinical structures/processes & 1.00 \\
\hline - A nurse who is able to prioritise complex and competing schedules and workload & 0.96 \\
\hline \multicolumn{2}{|l|}{ 8. Collaborator } \\
\hline - A nurse who collaborates effectively with a broad range of people regarding service provision & 1.00 \\
\hline - A nurse who works with service providers internal and external to health & 1.00 \\
\hline - A nurse who networks with internal and external service providers & 1.00 \\
\hline \multicolumn{2}{|l|}{ 9. Negotiator } \\
\hline $\begin{array}{l}\text { - A nurse who fosters working relationships across all sectors, including government, non-government and private service } \\
\text { providers }\end{array}$ & 1.00 \\
\hline - A nurse who facilitates and encourages multidisciplinary teamwork & 1.00 \\
\hline \multicolumn{2}{|l|}{ 10. Team member } \\
\hline $\begin{array}{l}\text { - A member of multidisciplinary teams encompassing acute, community, government and non-government organisations and } \\
\text { private business }\end{array}$ & 0.96 \\
\hline \multicolumn{2}{|l|}{ 11. Clinician } \\
\hline - A nurse who supports clients with a person centred approach & 0.96 \\
\hline
\end{tabular}


Table 6. Final list of role domains and associated role functions for the GPLN using the Delphi Technique

Co-ordinator of client/patient care

- A nurse who provides a liaison role between health care professionals to facilitate coordinated care

- A nurse who is a link between hospital and community

- A nurse expert in co-ordinating and facilitating inter-organisational case management

- A consultant in care co-ordination for health providers in the acute and community sectors of government and non-government organisation

- A nurse who facilitates health and community service access for people

- A nurse who facilitates interdisciplinary care plans

- A nurse who facilitates integrated health care across vulnerable populations

Educator

- A nurse who is seen by service providers as the person who can provide information about general practice

- A resource person to the hospital, community and general practice staff

- A provider of information regarding community support services

- A nurse who gathers and disseminates information using a variety of systems and programs

- A researcher in the latest information regarding best practice for integrated care co-ordination for complex and vulnerable populations

Communicator

- A nurse who improves communication between the hospital, community health and general practice

- A Nurse who maintains ongoing communication between care and service providers regarding client/patient care

- A nurse with excellent communication and negotiation skills

Advisor

- A nurse who is seen by service providers as a person who can provide information on referral pathways for clinical and psychosocial services

- A supporter of primary health care providers and care givers in navigating the health care system

- A nurse who can advise on current NSW Ministry of Health and local health programs and initiatives for target groups of people

Advocate

- A nurse who empowers people to navigate the health care and community support systems

- An advocate for clients/patients, their families and caregivers

- A nurse who is a member of committees who promote the health and wellbeing of people and communities

Change agent

- A nurse who identifies gaps in services/programs

- A nurse who contributes to ongoing quality improvement in service industry

- A nurse who facilitates change

Manager

- A nurse who contributes to the development of clinical structures/processes

- A nurse who is able to prioritise complex and competing schedules and workload

Collaborator

- A nurse who collaborates effectively with a broad range of people regarding service provision

- A nurse who works with service providers internal and external to health

- A nurse who networks with internal and external service providers

Negotiator

- A nurse who fosters working relationships across all sectors, including government, non-government and private service providers

- A nurse who facilitates and encourages multidisciplinary teamwork

Team member

- A member of multidisciplinary teams encompassing acute, community, government and non-government organisations and private business Clinician

- A nurse who supports clients with a person centred approach

This study highlights the important roles that communicator, collaborator, negotiator, team member and advocate roles play in ensuring the providers, patients and their families and carers are involved in planning and delivery of person centred care, fulfilled by the clinician role. Van der Watt ${ }^{[10]}$ recognised that communication and negotiation are amongst the inherent skills required of the liaison nurse to create constructive working environments for patients and health professional teams. The team member role may be an anomaly in this discussion as the GPLN works not only in their local community health team but across teams and therefore their role in this domain could also be that of a collaborator with 
a number of multidisciplinary teams. Communication is crucial in enabling the role domain of collaborator across teams which is essential in maintaining patient centred care in the community when patients are discharged from hospital. ${ }^{[9]}$ While the role domain of clinician may be contentious as it could clearly be part of the coordination role domain, it has been kept separate to clearly delineate these nurses as practitioners involved in managing patient centred care in the manager domain.

To facilitate a cultural change towards service integration and care coordination, the GPLNs see themselves as change agents. The GPLN's expert knowledge of local service provision, qualifies them to navigate through the complex array of service provision. Consequently, they assume the roles of advisor, educator and manager. Both Brunero et al. and Van der Watt described the mental health liaison nurse's role as being key in awareness raising and capacity and sustainability building amongst generalist nurses and the HealthOne GPLNs are described as leader and initiators of cultural change. ${ }^{[15]}$

\section{Implications for nursing}

This study has clarified the general role functions of the GPLN in the community setting. The position facilitates integrated care in local nursing and multidisciplinary teams as well as the broader team, which encompasses health and service providers in acute and community setting, spanning government, non-government and private. Role clarity for this position is important for management and relevant stakeholders in understanding how this role functions. Management could use the role functions identified in this study for staff appraisals to determine areas or skills requiring further development or as selection criteria for the recruitment of suitable applicants.

\section{Conclusions}

This study was limited in that it did not capture the nuances of the different roles and functions within the three distinct specialty groups of chronic and complex care, child and family, and mental health. Each of these specialties have discrete client cohorts requiring a specific service delivery approach. A further limitation was that the study was conducted in only two Local Health Districts in Sydney, therefore only a small sample was studied. However, small sample size is not uncommon in the Delphi Technique and doing three rounds can provide rigor to the final conclusions of a study. o As suggested by some authors, internal and external validity of the method is difficult to achieve; but it does provide a starting point. Hasson \& Keeney and the use of content validity greater than $70 \%$ as utilised in this study, adds to its rigor and usefulness. ${ }^{[25,26]}$

As found in previous studies, GPLNs are "pivotal" to improving integrated care for patients with complex social issues and care needs. ${ }^{[15,16]}$ The role of the GPLN is important for the safe integration of patient/client care in the community through co-ordinated/ integrated care incorporating all domains and functions of the role described in this study. Further clarification of the role needs to be continued using a larger sample across state boundaries.

\section{ACKNOWLEDGEMENTS}

The authors would like to acknowledge the editing and technical support provided by Dr Irene Chen.

\section{Conflicts of Interest Disclosure}

No conflict of interest has been declared by the authors.

\section{REFERENCES}

[1] Goodwin N, Smith J, Davies A, et al. A report to the Department of Health and the NHS Future Forum- Integrated care for patients and populations: Improving outcomes by working together. London: King's Fund; 2012.

[2] AHPA. Chronic Disease Management: Sharing the Care and Understanding between General Practice and Allied Health Providers. 2010.

[3] NSW Department of Health, Guidelines for Developing HealthOne NSW Services. 2012.

[4] Taylor MP, Readman S, Hague B, et al. A district epilepsy service, with community-based specialist liaison nurses and guidelines for shared care. Seizure. 1994. 3(2): 121-127. http://dx.doi.org/1 $0.1016 / \mathrm{S} 1059-1311$ (05)80202-X

[5] Thapar AK, Stott N, Richens A, et al. Attitudes of GPs to the care of people with epilepsy. Family Practice. 1998. 15(5): 437-442. PMid:
9848430. http://dx.doi.org/10.1093/fampra/15.5.437

[6] Shickle D, Hapgood R, Qureshi N. The genetics liaison nurse role as a means of educating and supporting primary care professionals. Family practice. 2002; 19(2): 193-196. http://dx.doi.org/10. 1093/fampra/19.2.193

[7] Kirker S, Young E, Warlow C. An evaluation of a multiple sclerosis liaison nurse. Clinical Rehabilitation. 1995; 9(3): 219-226. http://dx.doi.org/10.1177/026921559500900307

[8] Brunero S, Lamont S. Health behaviour beliefs and physical health risk factors for cardiovascular disease in an outpatient sample of consumers with a severe mental illness: A cross-sectional survey. International journal of nursing studies. 2010; 47(6): 753-760. PMid: 19959166. http://dx.doi.org/10.1016/j.ijnurstu. 2009.11.004

[9] Stokes B. Review of the admission or referral to and the discharge and transfer practices of public mental health facilities/services in 
Western Australia. 2012.

[10] Van Der Watt G. Consultation-liaison nursing: A personal reflection. Contemporary nurse. 2010; 34(2): 167-176. PMid: 20509801. http://dx.doi.org/10.5172/conu.2010.34.2.167

[11] Donald I, Berman P. Geriatric outpatient clinics: an audit of clinical action, transport and general practitioners' views. Age and ageing. 1989; 18(4): 253-257. http://dx.doi.org/10.1093/ageing/ 18.4 .253

[12] Shortus TD, Coulson ML, Blakeman TM, et al. An aged care liaison nurse can facilitate care planning using the Enhanced Primary Care items. Australasian Journal on Ageing. 2005; 24(2): 67-68. http://dx.doi.org/10.1111/j.1741-6612.2005.00076.x

[13] Dunnion ME, Kelly B. From the emergency department to home. Journal of clinical nursing. 2005. 14(6): 776-785. PMid: 15946286. http://dx.doi.org/10.1111/j.1365-2702.2005.01129.x

[14] McNab J, Mallit K-A, Gillespie J, et al. Report of the Evaluation of HealthOne Mount Druitt. Menzies Centre for Health Policy. 2013.

[15] Mcnab J, Paterson J, Fernyhough J, et al. Role of the GP liaison nurse in a community health program to improve integration and coordination of services for the chronically ill. Australian journal of primary health. 2015. PMid: 25704062.

[16] Bloomfield JG, Gordon CJ, Williams AM, et al. Nursing students' intentions to enter primary health care as a career option: Findings from a national survey. Collegian. 2015. PMid: 26281403. http://dx.doi.org/10.1016/j.colegn.2015.02.001

[17] NSW Department of Health. NSW Chronic Care Program strengthening general practitioner involvement in chronic care: review and recommendations. 2005.
[18] Department of Health: Chronic Disease Management (formerly Enhanced Primary Care or EPC) - GP services. 2014 [cited 2015 02/05/2015]. Available from: http: //www .health.gov.au/internet/main/publishing.n sf/Content/mbsprimarycare-chronicdiseasemanagement

[19] Australian Government Department of Health and Ageing, Guidelines for the Divisions Network Nursing in General Practice Program. Australian Government Department of Health and Ageing. 2006.

[20] Wilkes L. Using the Delphi technique in nursing research. Nursing Standard. 2015; 29(39): 43-49. PMid: 26015141. http://dx.doi .org/10.7748/ns.29.39.43.e8804

[21] Lindeman CA. Delphi survey of priorities in clinical nursing research. Nursing research. 1975; 24(6): 434-441. PMid: 1042714. http://dx.doi.org/10.1097/00006199-197511000-00006

[22] Keeney S, McKenna H, Hasson F. The Delphi technique in nursing and health research. John Wiley \& Sons. 2010.

[23] White K, Wilkes L. The specialist breast care nurse: an evolving role. Collegian. 1999; 6(4): 8-13. http://dx.doi.org/10.1016/S13 22-7696 (08)60603-4

[24] Cloninger CR, Salvador-Carulla L, Kirmayer LJ, et al. A time for action on health inequities: foundations of the 2014 Geneva declaration on person-and people-centered integrated health care for all. International Journal of Person Centered Medicine. 2015; 4(2): 69-89.

[25] Linstone HA, Turoff M. The Delphi Method. Techniques and applications. 2002; 53.

[26] Hasson F, Keeney S, Enhancing rigour in the Delphi technique research. Technological Forecasting and Social Change. 2011; 78(9): 1695-1704. 